https://helda.helsinki.fi

Outcome of transition phase patients with juvenile idiopathic arthritis

\author{
Relas, Heikki
}

2018

Relas , H , Luosujarvi , R \& Kosola , S 2018 , ' Outcome of transition phase patients with juvenile idiopathic arthritis ' , Modern Rheumatology , vol. 28 , no. 5 , pp. 832-837 . https://doi.org/10.1080/14397595

http://hdl.handle.net/10138/311366

https://doi.org/10.1080/14397595.2017.1416890

acceptedVersion

Downloaded from Helda, University of Helsinki institutional repository.

This is an electronic reprint of the original article.

This reprint may differ from the original in pagination and typographic detail.

Please cite the original version. 


\title{
Outcome of transition phase patients with juvenile idiopathic arthritis
}

Heikki Relas ${ }^{1}$, Riitta Luosujärvi ${ }^{1}$, and Silja Kosola ${ }^{2}$

\author{
${ }^{1}$ Rheumatology, Helsinki University Hospital and University of Helsinki, PL 372, 00029 \\ HUS, Finland \\ ${ }^{2}$ Children's Hospital, Helsinki University Hospital and University of Helsinki, PL 435, 00029 \\ HUS, Finland
}

Address for correspondence and reprint requests

Heikki Relas

Rheumatology, Helsinki University Hospital

PL 372

00029 HUS

Finland

heikki.relas@gmail.com

tel. +358504274869

Number of text pages: 21

Number of tables and table legends: 5

Key words: adolescents, juvenile idiophatic arthritis, disease-modifying antirheumatic drugs, transition of care, smoking 


\begin{abstract}
Objectives: Across diagnosis groups, successful transition of adolescent and young adults from children's hospitals to adult care is often associated with decreased treatment adherence and treatment results. The aim of this study was to characterize disease activity and antirheumatic medications following transfer of care of juvenile idiopathic arthritis (JIA) patients to the adult clinic.
\end{abstract}

Method: All consecutive JIA patients aged 16 to 20 years who visited the specific transition clinic in the rheumatology outpatient clinic of Helsinki University Hospital between November 2012 and May 2013 and between April 2015 and April 2016 were evaluated.

Results: A total of 214 patients were identified, and 23 appeared in both cohorts. Females had higher disease activity scores than males (DAS28 $1.9 \pm 0.7$ vs. $1.6 \pm 0.3, \mathrm{P}=0.019$; and DAS44 $1.0 \pm 0.7$ vs. $0.7 \pm 0.5, \mathrm{P}=0.005$; respectively) in the latter cohort. Disease-modifying antirheumatic drugs (DMARDs) were prescribed to $86 \%$ of patients, and $48 \%$ were on biological DMARDs (bDMARDs), whereas 14\% had no specific treatments.

Conclusions: Disease activity and clinic attendance remained stable during the transition period. The proportion of transition phase JIA patients on bDMARDs was high and disease activity was low. Reasons for lower disease activity in males in the latter cohort require further investigation. 


\section{Introduction}

Juvenile idiopathic arthritis (JIA) is a group of arthritides that emerge before the age of 16 (1). The incidence of JIA in the Nordic countries is 15-19.5/100 000 (2). The course of disease varies from self-limiting monoarthritis to chronic destructive forms of polyarthritis (3). Up to $50 \%$ of JIA patients were not in remission eight years after diagnosis in a Nordic populationbased study (4), and radiological joint damage may be as common as in adult onset rheumatoid arthritis (5). Although the prognosis of JIA has improved in the past decades (6), transition from pediatric care to an adult clinic is a challenging time period for maintaining a good doctor-patient relationship as well as continuity of treatments and satisfactory disease control. Transitional care programs have been developed to meet the special needs of adolescent patients (7-10), and recommendations for the transition of care of young people with JIA have been published recently (11). However, evidence on the outcome and medications of transition phase (16-24 years) patients are still limited.

The transition process spans several years and is composed of three phases: I) preparation of the patient and family for the transfer of care from pediatricians to adult specialists, II) actual transfer of care with close collaboration of specialists involved in patient care, and finally, III) follow-up at the adult clinic (7). During the third phase, patients still require special attention from service providers due to the patients' young age, gradually increasing autonomy and great differences in maturation between individuals. The last phase of transition has, however, often been the "weakest link" for many different diagnosis groups.

To assess treatment protocols and results after the establishment of a transition clinic in adult rheumatology, we investigated the disease activity and medications of transition phase JIA patients at the Helsinki University Hospital (HUH) adult rheumatology clinic. We hypothesized that treatment results would gradually improve after the establishment of a 
transition clinic in adult services and that close collaboration with pediatricians would decrease the need for changes in medication after the transfer of care.

\section{Materials and Methods}

\section{Transition process development}

The HUH rheumatology outpatient transition clinic was instituted in 2011. Transition phase patients visit the clinic on Tuesdays and one adult rheumatologist and one nurse are responsible for their care. Transitional patients visit the clinic usually every 6-9 months, and visits at the transition clinic usually continue up to the age of 20 years. Thereafter follow-up depends on the patients' clinical status and ongoing medications. Patients on diseasemodifying antirheumatic drugs (DMARD) are usually followed by adult rheumatologists either at HUH or local hospitals, whereas patients with inactive disease are referred to general practitioners. Before the launch of a transition clinic, transition phase patients had no particular doctor or nurse appointed to them.

\section{Patient cohort}

Practically all JIA patients who require follow up after treatment by specialists in pediatric rheumatology in Southern Finland are referred to the HUH rheumatology outpatient transition clinic, which has a background population of 1.6 million. Transition of rheumatology patients from pediatric to adult specialists occurs based on individual assessment at the age of 16-18 years. Since public health care in Finland is based on national social security, insurance type or coverage is irrelevant. 
Using the patient registry of our hospital, we identified two diagnosis groups (ICD-10 codes M08.0-M08.9 and M09.0*L40.5) that included all of the JIA patients aged 16 to 20 years who visited the HUH rheumatology outpatient transition clinic. To compare cohort effects, we gathered data on patients who attended the transition clinic between November 2012 and May 2013 (Cohort 2013) and between April 2015 and April 2016 (Cohort 2015).

\section{Clinical data}

We conducted a meticulous review of patient records and collected data on previous and ongoing medications. Disease outcome was evaluated by the health assessment questionnaire disability index (HAQ) (12) and disease activity scores (DAS) $28(13,14)$ and DAS44 (15, 16). The DAS-CRP is a modification of the DAS28. Originally the DAS28 includes the measured erythrocyte sedimentation rate (ESR) value, while the DAS-CRP uses the serum CReactive Protein (CRP) instead. In this study, DAS28 refers to DAS-CRP. Bath ankylosing spondylitis disease activity index (BASDAI) (17) was used in patients with enthesitis related arthritis (ERA) (ICD-10 code M08.1).

The HAQ assesses the patient's ability to perform 20 activities of daily living with four response options (from "without any difficulty" to "not able to do"; respective scores ranging from 0 to 3). These activities are classified into eight categories, and the category score is the highest score of any activity within the category. The total HAQ score is the mean of the category scores. HAQ was not routinely collected at our center in 2013 and could only be analyzed in the 2015 cohort. Because ankle affection is a common feature in JIA, DAS44 which includes also joints distal to the knees, was used in addition to DAS28. Remission was defined as DAS28 <2.6 (14) and DAS44 < 1.6 (18). Juvenile arthritis DAS or other pediatric 
measures were not included. Longitudinal data was obtained for 23 patients who were present in both cohorts.

\section{Ethics}

Data were collected retrospectively from patient records. Thus approval by the ethics committee was not required for this study at our center.

\section{Statistical methods}

Data are presented as mean \pm standard deviation (SD) for continuous variables, or in case of skewed distribution, median with range. For categorical variables, percentages are reported. T-tests were used for comparisons between normally distributed continuous variables.

Nonparametric tests were used when distributions were skewed and with nominal values. A pvalue $<0.05$ was considered statistically significant. Data analyses were performed using IBM SPSS Statistics 22 (IBM, Somers, NY). 


\section{Results}

A total of 214 patients were identified and 23 of them were present in both cohorts. The cohorts were similar in regard to age, gender distribution, and duration of the disease (Table 1). Disease duration ranged from one to 18 years. Three patients also had diabetes mellitus and two Down's syndrome. The majority of patients had juvenile oligoarthritis or polyarthritis, and 7-8\% were rheumatoid factor (RF) positive (Table 1). One patient had arthritis associated with colitis ulcerosa. In the rest arthritis was unclassified. A quarter of the patients had a history of uveitis, and the presence of positive antinuclear antibodies (ANA) correlated with uveitis $(\mathrm{p}<0.001)$. The proportion of HLAB27 positive patients was high especially in the 2013 cohort. Clinical data are presented in Table 2 . Up to $17 \%$ of patients in the 2013 cohort smoked at least occasionally, whereas only $6 \%$ of the patients in the 2015 cohort were smokers $(\mathrm{P}=0.002)$. The no show rate was $11 \%$ in both cohorts, and these patients were instructed to contact the outpatient clinic for a new appointment.

\section{Disease activity}

In the whole study population, disease activity was low, and only three patients had undergone surgery for rheumatic manifestations. Median HAQ was 0 (range 0-1.5). According to both DAS28 and DAS44 remission criteria, $89 \%$ of patients were in remission. Disease activity parameters according to gender are presented in Table 2 for both cohorts. DAS28 was $1.8 \pm 0.7$ and DAS44 was $0.9 \pm 0.6$ in JIA patients other than ERA. The BASDAI of ERA patients was low in the whole population (median 1.3, range 0-8.2). HAQ and DAS28 were similar in RF-positive and RF-negative patients. The HLAB27 status showed no association with disease activity parameters or treatment regimens. 
Medication during the transition phase

In the 2013 cohort, $83 \%$ of the patients used antirheumatic medication. Almost half (48\%) used biological DMARDs (bDMARDs), while 39\% used a combination of synthetic DMARDs and bDMARDs, and 9\% were on bDMARD monotherapy. The most commonly used synthetic DMARDs were methotrexate (MTX, 54\%), hydroxychloroquine (12\%) and sulfasalazine (11\%). Only $4 \%$ of patients used oral glucocorticoids, and $12.5 \%$ received intraarticular injections at the clinic. In general, antirheumatic medication remained the same in the 2015 cohort (Table 2) but some changes occurred in the use of bDMARDs over time (Table 3). Compared to the medication at the last appointment at the children's hospital, 57\% of patients on bDMARDs continued using the same bDMARD, 22\% had started a bDMARD, 13\% had switched the bDMARD, and 9\% had stopped using bDMARDs. All medications were discontinued from $10 \%$ of patients who had DMARD treatments at their last visit at the children's hospital. No significant differences were found between the 2013 and 2015 cohorts. In the 2015 cohort, etanercept was the most common first bDMARD (49\%) followed by adalimumab, golimumab, and infliximab (17\% each) whereas adalimumab was the most common second-line bDMARD and golimumab the most common third-line bDMARD.

All patients with seropositive JIA were females, and the onset of the disease was at an older age (Table 4). In the 2013 cohort, RF positive patients were more often on bDMARDs than RF negative patients ( $88 \%$ vs. $45 \%, \mathrm{P}=0.02)$, but their use of synthetic drugs was similar.

Twenty-three patients were present in both cohorts. Their clinical status remained stable during follow-up (Table 5). Nine patients underwent changes to their bDMARD treatment. Four patients' bDMARD was terminated, two due to a side-effect and two because of longstanding remission. In three cases bDMARD was switched to another product due to 
insufficient efficacy, and two patients' commenced bDMARD treatment during the follow-up period. 


\section{Discussion}

In this retrospective study, transition phase JIA patients had both low disease activity and a low degree of disability, and treatment results remained stable between two study cohorts. Patients commonly received highly individualized bDMARD-based treatment.

Treatment of adolescents with chronic diseases is challenging. Special transition outpatient clinics have been instituted in many rheumatology clinics to provide better transitional care for adolescents, but a need for improving transition care remains (19). At HUH, one rheumatologist and one nurse are available for transition stage patients at the adult clinic once a week. Treatment and appointments can be tailored according to the individual patient's needs, e.g. appointment duration can be one hour instead of the routine 30 minutes if required. In addition, patients may contact a rehabilitation counsellor, social worker, physiotherapist or occupational therapist, who are also available after the doctor's appointment.

Our study cohorts represent the local treatment strategies and patient outcomes during the last phase of transition since practically all JIA patients with ongoing disease activity from the metropolitan Helsinki area enter the HUH transition outpatient clinic at the age of 16 to 18 years. However, this study cohort does not represent the whole JIA population of the respective area because JIA patients without DMARD treatment are commonly transferred to general practitioners. The prevalence of HLAB27 in our cohort was higher than that in a previous study of JIA patients (20). HLAB27 positive JIA patients with a more severe disease may be overrepresented in our study population, since JIA patients with less severe disease may have been transferred to other hospitals already by the age of 20 years. In addition, the small number of follow-up patients in this retrospective study limits evaluation of disease 
course during follow-up. In the future, routinely collected quality of life measures will provide more information.

According to earlier studies $(3,4)$, many JIA patients have ongoing disease activity and subsequent functional impairment in adulthood. Treatment outcomes with a more recent diagnosis, more active treatment and enhanced transition programs, however, seem to have improved (21). Up to one-third of patients have reported functional limitations (22) and they are at higher risk for unemployment (23). Although JIA and rheumatoid arthritis are different diseases, both of them can cause severe joint damage if untreated. High rates of radiographic hip damage have been reported in young adults (20-31 years) with polyarticular JIA (5). Evidence suggests that active treatment of arthritis is beneficial in JIA (24-26). Strict disease control may explain the low degree of functional impairment and disability in the present study population. Almost all seropositive patients were on bDMARDs and reported no significant functional impairment. The relapse rate after termination of DMARDs is substantial in JIA (27). Whether it is possible to taper these medications in early adulthood remains to be studied.

Among our patients, disease activity of male patients was lower than that of females especially in the latter cohort. Previous studies have shown that the cumulative number of affected joints in females with JIA is higher than in males and that HLAB27 predicts a more severe disease course $(20,28)$. Female gender is also associated with more pain and poorer function in JIA (29). In our study, females reported more pain although treatment strategies were similar between the sexes. Pain alone fails to explain the higher DAS28 and DAS44 in females. The cause for lower disease activity in males in the latter cohort remains unknown, 
but possible explanations may be related to treatment adherence and require further investigation.

Disease activity measured by DAS28 and DAS44 gave similar results, and we found no specific indications to use the DAS44 in JIA patients. We found no difference in rates of smoking between genders but smoking decreased from cohort 2013 to cohort 2015. This may reflect a similar trend as in the general population of young Finns (30).

In a recent cross-sectional study of Finnish adult outpatient rheumatology clinics (31), $21 \%$ of rheumatoid arthritis patients used bDMARDs, which is clearly less than the proportion of transition phase patients using bDMARDs in our study (48\%). However, only $52 \%$ of adult patients were in DAS28 remission compared to $89 \%$ of patients in the present study. In addition, the median time from diagnosis was shorter in the adult population (7.2 years) than among our JIA patients (8.4 years). In another recent study from Tampere, Finland, only 29\% of adolescent and young adult JIA patients were on bDMARDs and $58 \%$ of patients had some disease activity within the past year (32). The use of bDMARDs in our cohort is in concordance to a French study (33), where up to $50 \%$ of transitional JIA patients were on bDMARDs. It is possible that adolescents with long life expectancy may be treated more actively than adult patients in an attempt to avoid future disability and during a developmental stage that possibly increases vulnerability to autoimmunity (34). Golimumab had become the most popular bDMARD already in the 2015 cohort although it has only been indicated in the treatment of JIA since 2016. According to a Finnish register study (35), only 5.8\% of adult patients on bDMARDs between 2004 and 2014 used golimumab. Especially for young patients, the once in a month dosing regimen of golimumab may often be an attractive alternative to the other bDMARDs which require injections every 1-2 weeks and may even enhance treatment adherence. 
In conclusion, high rates of clinic attendance and remission and low disease activity as well as a good functional status can be achieved by strict disease control, treatment strategies that are attractive to patients and enhanced doctor-patient relationships in transition phase JIA patients. Through enhanced care transitions, avoiding future joint damage and functional impairment become realistic goals. Prospective studies are still needed to evaluate the longterm effects of bDMARD treatments on JIA populations reaching adulthood and whether successful tapering of DMARDs in adulthood is conceivable. Our study highlights that in the treatment of adolescents and young adults, special knowledge, communication skills and clinics are required to reach optimal treatment results.

Conflicts of Interest

There are no financial or other conflicts of interest. 
Table 1. Clinical characteristics of the study cohorts.

\begin{tabular}{|c|c|c|c|}
\hline & $\begin{array}{l}\text { Cohort } 2013 \\
(n=109)\end{array}$ & $\begin{array}{l}\text { Cohort } 2015 \\
(n=128)\end{array}$ & \\
\hline Age, years & $17(16-20)$ & $17(16-20)$ & \\
\hline Females, n (\%) & $74(68)$ & $91(71)$ & \\
\hline Disease duration, years & $8.0(1-18)$ & $7.5(1-19)$ & \\
\hline Time since transfer of care, months & $18(2-56)$ & $18(2-56)$ & \\
\hline RF positive, $\%$ & 7 & 8 & \\
\hline ANA positive, $\%$ & 33 & 32 & \\
\hline HLAB27 positive, $\%$ & 43 & 35 & \\
\hline History of uveitis, $\%$ & 25 & 25 & \\
\hline \multicolumn{4}{|l|}{ Diagnoses, $\%$} \\
\hline Seropositive (M08.0) & 7 & 9 & \\
\hline Enthesitis related arthritis (M08.1) & 12 & 13 & \\
\hline Polyarthritis (M08.3) & 33 & 31 & \\
\hline Oligoarthritis (M08.4) & 39 & 40 & \\
\hline Psoriatic arthritis & 6 & 4 & \\
\hline Smoking, n (\%) & 17 & 6 & $\mathrm{P}=0.002$ \\
\hline
\end{tabular}

Age, disease duration and time since transfer of care presented as median (range). RF, rheumatoid factor; ANA, antinuclear antibodies. 
Table 2. Characteristics and disease outcome parameters of females and males with juvenile idiopathic arthritis (JIA).

\section{Cohort $2013 \quad$ Cohort 2015}

\begin{tabular}{|c|c|c|c|c|}
\hline & Females, n=74 & Males, $n=35$ & Females, $n=91$ & Males, $n=37$ \\
\hline Height, $\mathrm{cm}$ & $162 \pm 7$ & $179 \pm 6 * *$ & $163 \pm 7$ & $176 \pm 0 * *$ \\
\hline Weight, kg & $58.3 \pm 10.9$ & $68.7 \pm 10.0$ & $59.4 \pm 10.9$ & $68.6 \pm 15.8$ \\
\hline $\mathrm{BMI}, \mathrm{kg} / \mathrm{m} 2$ & $22.0 \pm 4.3$ & $21.6 \pm 2.9$ & $22.3 \pm 4.5$ & $22.0 \pm 3.0$ \\
\hline RF positive, n (\%) & $7(9 \%)$ & $1(3 \%)$ & $10(11 \%)$ & $0(0 \%)$ \\
\hline $\mathrm{CRP}, \mathrm{mg} / \mathrm{l}$ & $1(1-83)$ & $1(0-100)$ & $1(1-57)$ & $1(0-7)$ \\
\hline $\mathrm{ESR}, \mathrm{mm} / \mathrm{h}$ & $7(1-40)$ & $2(0-54)$ & $7(2-57)$ & $2(0-17) * *$ \\
\hline Swollen joints & $0(0-9)$ & $0(0-9)$ & $0(0-6)$ & $0(0-4)$ \\
\hline Tender joints & $0(0-11)$ & $0(0-6)$ & $0(0-1)$ & $0(0-4)$ \\
\hline VAS pain, mm & $12(0-88)$ & $8(0-65)$ & $15(0-90)$ & $3(0-65)^{*}$ \\
\hline DAS28 & $2.1 \pm 1.0$ & $2.0 \pm 1.0$ & $1.9 \pm 0.7$ & $1.6 \pm 0.3 *, \#$ \\
\hline DAS44 & $1.1 \pm 0.9$ & $0.8 \pm 0.7$ & $1.0 \pm 0.7$ & $0.7 \pm 0.5^{*}$ \\
\hline MTX, n (\%) & $45(60)$ & $14(40)$ & $51(56)$ & $14(38)$ \\
\hline bDMARD, n (\%) & $32(43)$ & $20(57)$ & $41(45)$ & $13(35)$ \\
\hline Smoking, n (\%) & $12(16)$ & $7(20)$ & $5(6)^{\#}$ & $2(5)$ \\
\hline
\end{tabular}

Values are presented as mean \pm standard deviation except for VAS pain, CRP, ESR, and swollen and tender joints for which median (range) is provided. BMI, body mass index; RF, rheumatoid factor; CRP, C-reactive protein; ESR, erythrocyte sedimentation rate; VAS visual analogic scale; DAS, disease activity score; MTX, methotrexate; bDMARD, biological disease modifying anti-rheumatic drug. $* \mathrm{P}<0.05$ for difference between sexes. $* * \mathrm{P}<0.01$ for difference between sexes. \# $\mathrm{P}<0.05$ for difference between cohorts. 
Table 3. Use of bDMARDs in the 2013 and 2015 cohorts.

\begin{tabular}{l|lll}
\hline & Cohort 2013 $(n=52)$ & Cohort 2015 $(n=54)$ & Change, \% \\
\hline Adalimumab & $23(44)$ & $10(19)$ & -58 \\
Certolizumab & $2(4)$ & $1(2)$ & -50 \\
Etanercept & $19(37)$ & $15(28)$ & -24 \\
Golimumab & $5(10)$ & $22(41)$ & +324 \\
Infliximab & - & $2(4)$ & \\
Abatacept & $2(4)$ & $1(2)$ & -50 \\
Rituximab & $1(2)$ & - & \\
Tocilizumab & - & $3(6)$ & \\
\hline
\end{tabular}

$\mathrm{n}(\%)$. 
Table 4. Characteristics and disease outcome parameters of patients with seronegative and seropositive juvenile idiopathic arthritis (JIA).

\begin{tabular}{lll}
\hline & $\begin{array}{l}\text { Seronegative, } \\
\mathrm{n}=197\end{array}$ & $\begin{array}{l}\text { Seropositive } \\
\mathrm{n}=17\end{array}$ \\
\hline Females, n (\%) & $131(66 \%)$ & $17(100)^{*}$ \\
BMI, kg/m & $22.1 \pm 4.3$ & $21.3 \pm 2.6$ \\
Age at diagnosis, years & $10(1-16)$ & $13(2-15)^{*}$ \\
ANA positive, n $(\%)$ & $55(33)$ & $3(20)$ \\
HLAB27 positive, n (\%) & $106(60)$ & $2(17)$ \\
History of uveitis, n (\%) & $52(26)$ & $2(13)$ \\
HAQ & $0(0-1.5)$ & $0(0-0.1)$ \\
DAS28 & $1.6(1.4-5.7)$ & $1.4(1.4-2.6)$ \\
VAS pain, mm & $10(0-90)$ & $5(0-6)$ \\
CRP, mg/l & $1(1-100)$ & $1(1-8)$ \\
ESR, mm/h & $5(0-57)$ & $5(2-23)$ \\
MTX, n $(\%)$ & $150(69)$ & $15(88)$ \\
bDMARD, n $(\%)$ & $86(43)$ & $11(65)$ \\
no DMARD, n $(\%)$ & $34(17)$ & $0(0)$ \\
Cortisone, n $(\%)$ & $6(3)$ & $0(0)$ \\
& &
\end{tabular}

Values are presented as median (range) except for mean \pm standard deviation for BMI (body mass index) unless otherwise stated. ANA, anti-nuclear antibodies; $\mathrm{HAQ}$, health assessment questionnaire; DAS28, disease activity score 28; VAS visual analogic scale; CRP, C-reactive protein; ESR, erythrocyte sedimentation rate; MTX, methotrexate; bDMARD, biological disease modifying anti-rheumatic drug. ${ }^{*} \mathrm{P}<0.05$ from RF negative. 
Table 5. Longitudinal data of 23 patients who appear in both cohorts

\begin{tabular}{l|ll}
\hline & 2013 & 2015 \\
\hline Time since transfer, months & $6(2-20)$ & $36(26-54)$ \\
DAS28 & $1.5(1.4-5.0)$ & $1.5(1.4-3.7)$ \\
VAS pain, mm & $9(0-88)$ & $10(0-90)$ \\
CRP, & $1(1-83)$ & $1(1-22)$ \\
ESR, mm/h & $9(2-34)$ & $7(2-35)$ \\
Swollen joints & $0(0-6)$ & $0(0-6)$ \\
Tender joints & $0(0-3)$ & $0(0-4)$ \\
bDMARDs, \% & 65 & 56 \\
s/bDMARDs, \% & 87 & 03 \\
Methotrexate, \% & 56 & 0 \\
Peroral cortisone, $\%$ & 13 & 17 \\
\hline Intra-articular cortisone, $\%$ & 22 & \\
\hline
\end{tabular}

Values are presented as median (range) unless otherwise stated. DAS28, disease activity score 28; VAS, visual analog scale; CRP, C-reactive protein; ESR, erythrocyte sedimentation rate; bDMARDs, biologic disease-modifying antirheumatic drugs; s/bDMARDs, synthetic or biologic disease-modifying antirheumatic drugs. 


\section{References}

1. Ravelli A, Martini A. Juvenile idiopathic arthritis. Lancet. 2007 Mar 3;369(9563):767-78.

2. Berntson L, Andersson Gare B, Fasth A, Herlin T, Kristinsson J, Lahdenne P, et al. Incidence of juvenile idiopathic arthritis in the nordic countries. A population based study with special reference to the validity of the ILAR and EULAR criteria. J Rheumatol. 2003 Oct;30(10):2275-82.

3. Hersh A, von Scheven E, Yelin E, Medscape. Adult outcomes of childhood-onset rheumatic diseases. Nat Rev Rheumatol. 2011 May;7(5):290-5.

4. Nordal E, Zak M, Aalto K, Berntson L, Fasth A, Herlin T, et al. Ongoing disease activity and changing categories in a long-term nordic cohort study of juvenile idiopathic arthritis. Arthritis Rheum. 2011 Sep;63(9):2809-18.

5. Elhai M, Bazeli R, Freire V, Feydy A, Drape JL, Quartier P, et al. Radiological peripheral involvement in a cohort of patients with polyarticular juvenile idiopathic arthritis at adulthood. J Rheumatol. 2013 Apr;40(4):520-7.

6. Stoll ML, Cron RQ. Treatment of juvenile idiopathic arthritis: A revolution in care. Pediatr Rheumatol Online J. 2014 Apr 23;12:13,0096-12-13. eCollection 2014.

7. Rosen DS, Blum RW, Britto M, Sawyer SM, Siegel DM, Society for Adolescent Medicine. Transition to adult health care for adolescents and young adults with chronic conditions:

Position paper of the society for adolescent medicine. J Adolesc Health. 2003 Oct;33(4):30911.

8. Tucker LB, Cabral DA. Transition of the adolescent patient with rheumatic disease: Issues to consider. Rheum Dis Clin North Am. 2007 Aug;33(3):661-72.

9. Hazel E, Zhang X, Duffy CM, Campillo S. High rates of unsuccessful transfer to adult care among young adults with juvenile idiopathic arthritis. Pediatr Rheumatol Online J. 2010 Jan $11 ; 8: 2,0096-8-2$.

10. Stringer E, Scott R, Mosher D, MacNeill I, Huber AM, Ramsey S, et al. Evaluation of a rheumatology transition clinic. Pediatr Rheumatol Online J. 2015 Jun 11;13:22,015-0016-x.

11. Foster HE, Minden K, Clemente D, Leon L, McDonagh JE, Kamphuis S, et al.

EULAR/PReS standards and recommendations for the transitional care of young people with juvenile-onset rheumatic diseases. Ann Rheum Dis. 2016 Nov 1.

12. Fries JF, Spitz P, Kraines RG, Holman HR. Measurement of patient outcome in arthritis. Arthritis Rheum. 1980 Feb;23(2):137-45.

13. Prevoo ML, van 't Hof MA, Kuper HH, van Leeuwen MA, van de Putte LB, van Riel PL. Modified disease activity scores that include twenty-eight-joint counts. development and validation in a prospective longitudinal study of patients with rheumatoid arthritis. Arthritis Rheum. 1995 Jan;38(1):44-8. 
14. Aletaha D, Smolen JS. The definition and measurement of disease modification in inflammatory rheumatic diseases. Rheum Dis Clin North Am. 2006 Feb;32(1):9,44, vii.

15. van der Heijde DM, van 't Hof MA, van Riel PL, Theunisse LA, Lubberts EW, van Leeuwen MA, et al. Judging disease activity in clinical practice in rheumatoid arthritis: First step in the development of a disease activity score. Ann Rheum Dis. 1990 Nov;49(11):91620.

16. van der Heijde DM, van 't Hof M, van Riel PL, van de Putte LB. Development of a disease activity score based on judgment in clinical practice by rheumatologists. J Rheumatol. 1993 Mar;20(3):579-81.

17. Garrett S, Jenkinson T, Kennedy LG, Whitelock H, Gaisford P, Calin A. A new approach to defining disease status in ankylosing spondylitis: The bath ankylosing spondylitis disease activity index. J Rheumatol. 1994 Dec;21(12):2286-91.

18. Shammas RM, Ranganath VK, Paulus HE. Remission in rheumatoid arthritis. Curr Rheumatol Rep. 2010 Oct;12(5):355-62.

19. Ammerlaan JW, Scholtus LW, Bijlsma HJ, Prakken BJ, Kruize AA. An urge for change: Transitional care for young adults with juvenile idiopathic arthritis. Patient Educ Couns. 2013 Jul;92(1):127-9.

20. Berntson L, Damgard M, Andersson-Gare B, Herlin T, Nielsen S, Nordal E, et al. HLAB27 predicts a more extended disease with increasing age at onset in boys with juvenile idiopathic arthritis. J Rheumatol. 2008 Oct;35(10):2055-61.

21. Miyamae T, Tanaka E, Kishi T, Matsuyama T, Igarashi T, Fujikawa S, et al. Long-term outcome of 114 adult JIA patients in a non-pediatric rheumatology institute in japan. Mod Rheumatol. 2015 Jan;25(1):62-6.

22. Minden K, Niewerth M, Listing J, Biedermann T, Bollow M, Schontube M, et al. Longterm outcome in patients with juvenile idiopathic arthritis. Arthritis Rheum. 2002 Sep;46(9):2392-401.

23. Foster HE, Marshall N, Myers A, Dunkley P, Griffiths ID. Outcome in adults with juvenile idiopathic arthritis: A quality of life study. Arthritis Rheum. 2003 Mar;48(3):767-75.

24. Wallace CA, Huang B, Bandeira M, Ravelli A, Giannini EH. Patterns of clinical remission in select categories of juvenile idiopathic arthritis. Arthritis Rheum. 2005 Nov;52(11):3554-62.

25. Wallace CA, Giannini EH, Spalding SJ, Hashkes PJ, O'Neil KM, Zeft AS, et al. Trial of early aggressive therapy in polyarticular juvenile idiopathic arthritis. Arthritis Rheum. 2012 Jun;64(6):2012-21.

26. Tynjala P, Vahasalo P, Tarkiainen M, Kroger L, Aalto K, Malin M, et al. Aggressive combination drug therapy in very early polyarticular juvenile idiopathic arthritis (ACUTEJIA): A multicentre randomised open-label clinical trial. Ann Rheum Dis. 2011 Sep;70(9):1605-12. 
27. Verazza S, Negro G, Marafon D, Consolaro A, Martini A, Ravelli A. Possible discontinuation of therapies after clinical remission in juvenile idiopathic arthritis. Clin Exp Rheumatol. 2013 Jul-Aug;31(4 Suppl 78):S98,101; quiz S102-7.

28. Berntson L, Nordal E, Aalto K, Peltoniemi S, Herlin T, Zak M, et al. HLA-B27 predicts a more chronic disease course in an 8-year followup cohort of patients with juvenile idiopathic arthritis. J Rheumatol. 2013 May;40(5):725-31.

29. Taxter AJ, Wileyto EP, Behrens EM, Weiss PF. Patient-reported outcomes across categories of juvenile idiopathic arthritis. J Rheumatol. 2015 Oct;42(10):1914-21.

30. National Institute for Health and Welfare. Smoking in Finland. Available online at: https://www.thl.fi/fi/web/alcohol-tobacco-and-addictions/tobacco/smoking-in-finland Accessed March 2017

31. Aaltonen KJ, Sokka T, Mottonen T, Korpela M, Komulainen R, Uusitalo T, et al. A nationwide cross-sectional overview of patients with rheumatoid arthritis followed in outpatient specialty clinics in finland. Scand J Rheumatol. 2014;43(4):286-90.

32. Vidqvist KL, Malin M, Varjolahti-Lehtinen T, Korpela MM. Disease activity of idiopathic juvenile arthritis continues through adolescence despite the use of biologic therapies. Rheumatology (Oxford). 2013 Nov;52(11):1999-2003.

33. Wipff J, Sparsa L, Lohse A, Quartier P, Kahan A, Deslandre CJ. Impact of juvenile idiopathic arthritis on quality of life during transition period at the era of biotherapies. Joint Bone Spine. 2016 Jan;83(1):69-74.

34. Ngo ST, Steyn FJ, McCombe PA. Gender differences in autoimmune disease. Front Neuroendocrinol. 2014 Aug;35(3):347-69.

35. Aaltonen KJ, Joensuu JT, Pirilä L, Kauppi M, Uutela T, Varjolahti-Lehtinen T, et al. Drug survival on tumour necrosis factor inhibitors in patients with rheumatoid arthritis in Finland. Scand J Rheumatol 2016;1-5. 